\title{
Thermodynamic Activity of Sulfur in Tl-S Melt
}

\author{
By Noriyuki Fukuda*, Toshio Yokokawa**, \\ Shu-ichiro Nagai**** and Kichizo Niwa*****
}

\begin{abstract}
Vapor pressure of sulfur of sulfur-thallium liquid mixture was measured over the composition range of $0.55 \sim 0.98$ by mole fraction of sulfur. Although this mixture is much stable at the composition of $\mathrm{Tl}_{2} \mathrm{~S}$, sulfur activity is quite high and its partial molar heat of solution is positive in the intermediate range. This result was interpreted in terms of a modification of the sulfur chain on addition of thallium.

(Received January 6, 1972)
\end{abstract}

\section{Introduction}

Non-stoichiometric solid and liquid materials have been studied mainly on their electric properties. Binary systems of B-metals with chalcogen elements provide a plenty of examples of this sort, since they give homogeneous liquid solution over a wide range of composition at relatively low temperatures. Thus, they are the main part of the so-called liquid semiconductor ${ }^{(1)}$. However, the energy relation such as the interaction energy among the solutes and the cohesive energy have scarcely been investigated.

In the $\mathrm{Tl}-\mathrm{S}$ system, $\mathrm{Tl}_{2} \mathrm{~S}$ and $\mathrm{TIS}$ are the only compounds stable at room temperature, while the calorimetric data at elevated temperatures ${ }^{(2)}$ revealed that the enthalpy of solution of the two liquids shows a sharp minimum at the composition of $\mathrm{Tl}_{2} \mathrm{~S}$. As the solution of this composition is considered to be ionic to some extent, the character of the cohesive energy of the melt changes from the metallic $(\mathrm{Tl})$ through ionic $\left(\mathrm{Tl}_{2} \mathrm{~S}\right)$ to the molecular (S) nature as a function of composition. In this respect, the thermodynamic activity of the components is quite interesting. In the present study, the vapor pressure of sulfur was measured over the composition range $0.55 \sim 0.98$ by mole fraction of sulfur $\left(X_{\mathrm{S}}\right)$, and the activity of sulfur was discussed in relation to the structure.

\section{Experimental}

The dew point method was employed. Sulfur and thallium were sealed in vacuum in one end of a vycor glass tube of $1 \mathrm{~cm}$ diameter and $30 \mathrm{~cm}$ length. The tube was heated in an electric resistance furnace. A subsidiary heater and a device to inject cold air were introduced at the other end of the tube and in the inside wall sulf ur vapor was condensed at the dew point. Temperature measurements were made for the sample and the dew point relative to that of the sample. The

* Department of Chemistry, Faculty of Science, Hokkaido University, Sapporo. Present address : Mitsubishi Electric Co., Kitaitami, Japan.

** Department of Chemistry, Faculty of Science, Hokkaido University, Sapporo, Japan.

*** Graduate School, Hokkaido Universsity, Sapporo, Japan.

***** Hokkaido University, Sapporo, Japan. latter was determined from the mean value of temperatures at which a dew of sulfur appeared and disappeared. The temperature of the sample was kept constant within $\pm 1^{\circ} \mathrm{C}$, the dew point being determined with an accuracy of $\pm 0.3^{\circ} \mathrm{C}$. The purities of sulfur and thallium were 99.9999 and $99.99 \%$ respectively.

\section{Results and Discussion}

\section{Vapor pressure}

The experimental method is based on the assumption that the total pressure of sulfur for the melt is equal to that for pure sulfur at the dew point. It is assumed further that the vapors of $S_{2} \sim S_{8}$ are in equilibrium with each other depending upon temperature and total pressure. The total pressure of pure sulfur was quoted from the work of West and Menzies ${ }^{(3)}$. The temperature equation is given by

$$
\log P=-4830 / T-5.0 \log T+23.88 \text { (mmHg). (1) }
$$

The measured data are summarized in Table 1. Figure 1 shows the logarithms of the pressure as functions of the reciprocal of absolute temperature. A nearly linear relationship was obtained, with a change of slope at the two liquid boundary. The data in the two-liquid region are omitted in Table 1 . It was not made clear whether the melt of $X_{\mathrm{S}}=0.98$ is homogeneous in the experimental temperature range.

\section{Sulfur activity}

Detry et al. (4) determined the following equilibrium relation among the various species from mass-spectrometric measurement :

$$
\begin{array}{rlrl}
2 \mathrm{~S}(\mathrm{l}) & =\mathrm{S}_{2}(\mathrm{~g}) & \Delta G^{\circ}=28080-32.6 T, \\
2 \mathrm{~S}_{3}(\mathrm{~g})=3 \mathrm{~S}_{2}(\mathrm{~g}) & \Delta G^{\circ}=26600-36.6 T, \\
\mathrm{~S}_{4}(\mathrm{~g})=2 \mathrm{~S}_{2}(\mathrm{~g}) & \Delta G^{\circ}=28200-36.7 T, \\
2 \mathrm{~S}_{5}(\mathrm{~g})=5 \mathrm{~S}_{2}(\mathrm{~g}) & \Delta G^{\circ}=95500-114.4 T,
\end{array}
$$

(1) V. M. Glazov and S. N. Chizhevskaya: Liquid semiconductors, Plenum P., New York, (1969); Y. Nakamura : Bulletin J. Inst. Metals, 8 (1969), 610.

(2) T. Maekawa, T. Yokokawa and K. Niwa : J. Chem. Thermodynamics, 3 (1971), 707.

(3) W.A. West and A. W. Menzies : J. Phys. Chem., 33 (1929), 1880.

(4) D. Detry, J. Drowart, P. Goldfinger, H. Keller and H. Rickert: Z. Phys. Chem., N. F., 55 (1967), 134. 
Table 1 Dew points and Tl-S melts and the activity of sulfur.

\begin{tabular}{|c|c|c|c|}
\hline$X_{\mathrm{S}}$ & $\begin{array}{c}\text { Temperature } \\
\left({ }^{\circ} \mathbf{K}\right)\end{array}$ & $\begin{array}{c}\text { Dew point } \\
\left({ }^{\circ} \mathbf{K}\right)\end{array}$ & Activity \\
\hline 0.550 & $\begin{array}{l}630.8 \\
650.7 \\
694.3 \\
731.9 \\
771.0\end{array}$ & $\begin{array}{l}395.3 \\
405.0 \\
429.9 \\
450.3 \\
474.9\end{array}$ & $\begin{array}{l}0.154 \\
0.145 \\
0.141 \\
0.134 \\
0.136\end{array}$ \\
\hline 0.600 & $\begin{array}{l}651.7 \\
682.9 \\
701.2 \\
724.4\end{array}$ & $\begin{array}{l}422.7 \\
438.7 \\
452.3 \\
466.7\end{array}$ & $\begin{array}{l}0.220 \\
0.201 \\
0.208 \\
0.205\end{array}$ \\
\hline 0.650 & $\begin{array}{l}573.5 \\
625.8 \\
658.9 \\
708.2\end{array}$ & $\begin{array}{l}417.7 \\
449.0 \\
470.7 \\
502.6\end{array}$ & $\begin{array}{l}0.425 \\
0.418 \\
0.416 \\
0.403\end{array}$ \\
\hline 0.670 & $\begin{array}{l}578.9 \\
658.1 \\
696.2 \\
732.4 \\
792.0\end{array}$ & $\begin{array}{l}468.8 \\
519.7 \\
542.2 \\
558.2 \\
603.7\end{array}$ & $\begin{array}{l}0.609 \\
0.591 \\
0.571 \\
0.533 \\
0.520\end{array}$ \\
\hline 0.700 & $\begin{array}{l}482.3 \\
509.5 \\
533.6 \\
564.6 \\
584.7 \\
603.4 \\
622.8 \\
641.9 \\
662.0 \\
691.3 \\
724.6\end{array}$ & $\begin{array}{l}468.0 \\
487.9 \\
507.4 \\
529.1 \\
544.0 \\
555.8 \\
570.2 \\
581.2 \\
594.8 \\
609.3 \\
630.1\end{array}$ & $\begin{array}{l}0.930 \\
0.909 \\
0.900 \\
0.876 \\
0.864 \\
0.847 \\
0.837 \\
0.818 \\
0.805 \\
0.772 \\
0.747\end{array}$ \\
\hline 0.725 & $\begin{array}{l}651.1 \\
672.9 \\
707.3 \\
757.2 \\
837.0 \\
897.7\end{array}$ & $\begin{array}{l}635.6 \\
646.4 \\
665.4 \\
686.4 \\
721.2 \\
744.9\end{array}$ & $\begin{array}{l}0.945 \\
0.913 \\
0.869 \\
0.803 \\
0.700 \\
0.610\end{array}$ \\
\hline 0.750 & $\begin{array}{l}723.0 \\
742.8 \\
765.7 \\
807.3 \\
835.5\end{array}$ & $\begin{array}{l}719.8 \\
728.6 \\
739.9 \\
754.8 \\
764.1\end{array}$ & $\begin{array}{l}0.952 \\
0.922 \\
0.897 \\
0.827 \\
0.784\end{array}$ \\
\hline 0.800 & $\begin{array}{l}814.8 \\
837.6 \\
860.9 \\
887.8\end{array}$ & $\begin{array}{l}804.2 \\
810.8 \\
818.4 \\
825.5\end{array}$ & $\begin{array}{l}0.894 \\
0.857 \\
0.820 \\
0.775\end{array}$ \\
\hline
\end{tabular}

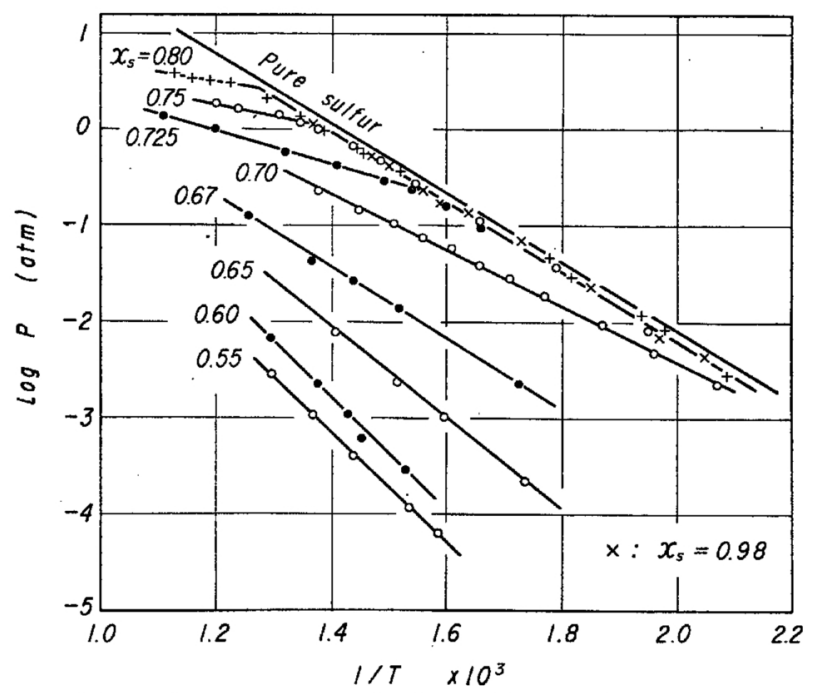

Fig. 1 Vapor pressure of sulfur of Tl-S melt as functions of temperature.

$$
\begin{aligned}
3 / 4 \mathrm{~S}_{8}(\mathrm{~g}) & =\mathrm{S}_{6}(\mathrm{~g}) & \Delta G^{\circ} & =6260-76 T, \\
7 / 8 \mathrm{~S}_{8}(\mathrm{~g}) & =\mathrm{S}_{7}(\mathrm{~g}) & \Delta G^{\circ} & =5770-72 T, \\
\mathrm{~S}_{8}(\mathrm{~g}) & =4 \mathrm{~S}_{2}(\mathrm{~g}) & \Delta G^{\circ} & =96800-1102 T .
\end{aligned}
$$

These equations are rearranged into the following form :

$$
{ }_{n} \mathrm{~S}(\mathrm{I})=\mathrm{S}_{n}(\mathrm{~g}), \quad p_{\mathrm{S} n}=K_{n} a_{\mathrm{S}}^{n}
$$

where $p_{\mathrm{S} n}, K_{n}$ and $a_{\mathrm{S}}$ are the vapor pressure of $\mathrm{S}_{n}$ (n-mer), the equilibrium constant of $S_{n}$ formation and the activity of sulfur in the solution respectively. The total pressure is the sum of these partial pressures, thus

$$
P=\sum_{n=2}^{8} p_{\mathrm{s} n}=\sum_{n=2}^{8} K_{n} a_{\mathrm{S}}^{n} .
$$

The activity of when walued from solving this 8-th order equation as to each experimental point with the aid of a computer (Table 1 ).* The activity interpolated at 667,800 and $870^{\circ} \mathrm{K}$ are shown in Fig. 2. It is to be noted that the activity lies quite low around $X_{\mathrm{s}}=0.5$ and increases sharply beyond $X_{\mathrm{S}}=0.65$. The temperature dependence is also high at this range. An alternative representation is given in Fig. 3, in which the partial molar quantities of solution of sulfur $\Delta \bar{G}_{\mathrm{S}}$ (=RT $\left.\ln a_{\mathrm{S}}\right), \Delta \bar{H}_{\mathrm{S}}$ and $T \Delta \bar{S}_{\mathrm{s}}$ at $667^{\circ} \mathrm{K}$ are plotted. The latter two were evaluated from the temperature dependence of the activity. The characteristic trends as seen in these figures are the following. (1) $\Delta \bar{H}_{\mathrm{S}}$ is positive within the experimental composition range and is likely to have a maximum at around $X_{\mathrm{S}}=0.8$, although it is to go down as low as $-6 \mathrm{kcal} / \mathrm{mol}$ at $X_{\mathrm{S}}=0.33^{(2)}$. (2) Yet, the activity is quite low below

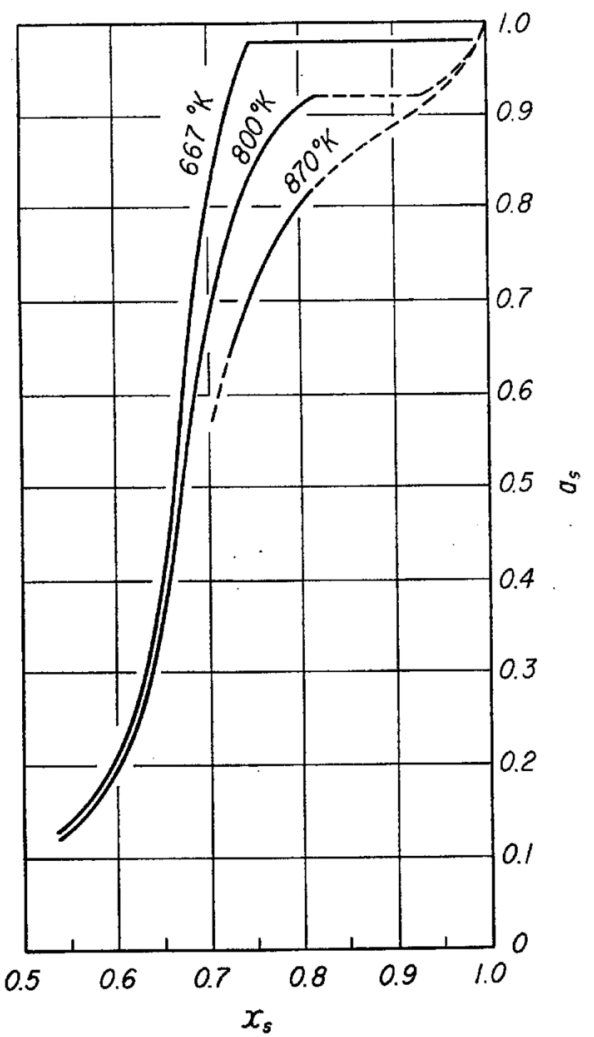

Fig. 2 Activity of sulfur of the Tl-S melt at temperatures of 667,800 and $870^{\circ} \mathrm{K}$.

* Operated by Hokkaido University Computing Center. 


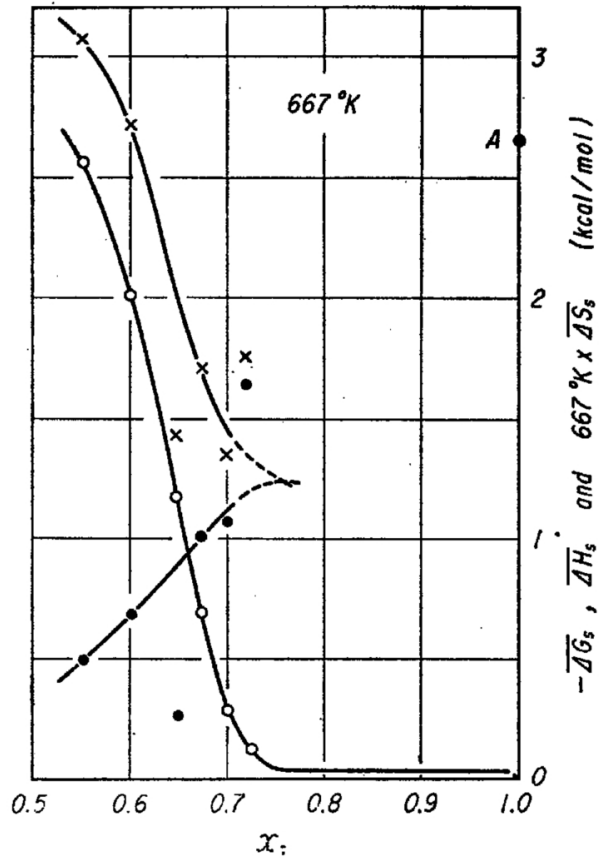

Fig. 3 Partial molar free energy, enthalpy and entropy of sulfur at $667^{\circ} \mathrm{K}$. See text for point $\mathrm{A}$.

$X_{\mathrm{S}}=0.65$. This means that in this range $\Delta \bar{S}_{\mathrm{S}}$ is much higher than a value calculated assuming a Tl-S ideal atomic mixture.

\section{Structural consideration}

These behaviors must be related to the structure of this melt. Above $160^{\circ} \mathrm{C}$ the liquid sulfur is composed of chain molecules of various lengths in addition to the

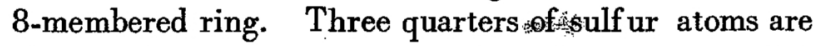
of chain form and the average chain length is as high as $8 \times 10^{3}$ by atomic unit at $670^{\circ} \mathrm{K}^{(5)}$. Keezer and Bailey ${ }^{(6)}$ found that thallium doping in selenium liquid leads to a terminal addition of thallium to the selenium chain or the formation of $\mathrm{Tl}-\mathrm{Se}_{n}-\mathrm{Tl}$ molecule. Recently, the structure of a $\mathrm{Tl}-\mathrm{Te}$ mixture was treated similarly by Cutler ${ }^{(7)}$. A similar reaction can be expected to occur in the sulfur-thallium system. On the other hand, liquid $\mathrm{Tl}_{2} \mathrm{~S}$ seem to be strongly ordered in nearest neighbour configuration due to its polar bonding,

(5) A. V. Tobolsky and S. Eisenberg : J. A. C. S., 81 (1959), 780.

(6) R. C. Keezer and M.W. Bailey : Materials Res. Bull., 2 (1967), 185.

(7) M. Cutler : Phil. Mag., 28 (1971), 401.

(8) R. J. Hodgkinson : ibid., 22 (1970), 1187 and ibid., 23 (1971), 673. regardless of whether it is composed of $\mathrm{Tl}_{2} \mathrm{~S}$ molecule as water of $\mathrm{H}_{2} \mathrm{O}$ molecule or it contains a cluster as postulated recently by Hodgikinson ${ }^{(8)}$. These suggest that the solution process of the present experiment may be visualised as a formation of $\mathrm{Tl}-\mathrm{S}_{n}-\mathrm{Tl}$ whose length depends on composition. Thus, above $X_{\mathrm{S}}=0.8$, both reactions of ring opening and chain scission

$$
\begin{gathered}
\mathrm{S}_{8}=\mathrm{S}_{8}^{*} \\
\mathrm{~S}_{n}^{*}=\mathrm{S}_{m}^{*}+\mathrm{S}_{n-m}^{*}
\end{gathered}
$$

take place on mixing before the reaction of

$$
2 \mathrm{Tl}+\mathrm{S}_{k}^{*}=\mathrm{Tl}-\mathrm{S}_{k}-\mathrm{Tl},
$$

where $S_{8}^{*}$ refers to sulfur chain (8-mer) ending with sulf ur radicals. The opening reaction (11) requires an extra energy over the scission reaction (12). Tobolsky and Eisenberg ${ }^{(5)}$ derived the difference to be 3.2 $\mathrm{kcal} / \mathrm{S}_{8} \mathrm{~g} \mathrm{~mol}$ or $0.4 \mathrm{kcal} / \mathrm{S} \mathrm{g}$ atom. Below $X_{\mathrm{S}}=0.8$ the mixing will be simply

$$
\begin{gathered}
\mathrm{Tl}-\mathrm{S}_{k}-\mathrm{Tl}+2 \mathrm{Tl}=\mathrm{Tl}-\mathrm{S}_{l}-\mathrm{Tl}+\mathrm{Tl}-\mathrm{S}_{k-l}-\mathrm{Tl}, \\
l<k<8
\end{gathered}
$$

The enthalpy of fictitious sulfur composed of only $\mathrm{S}_{8}^{*}$ would be higher than ordinary sulfur by $2.64 \mathrm{kcal} / \mathrm{mol}$ at this temperature (point $\mathrm{A}$ in Fig. 3) as is calculated from the heats of reactions (11) and (12) with the equilibrium concentrations of $S_{8}, S_{8}^{*}$ and chains at 670 ${ }^{\circ} \mathrm{K}^{(5)}$. Therefore the experimental values of $\Delta \bar{H}_{\mathrm{S}}$ is negative throughout the composition range relative to this $\mathrm{S}_{8}^{*}$ liquid. The partial molar entropy of solution of sulfur is also favourable to this sort of reasoning, although the limited range of measurement and the scattering of data make it ambigious. Thus, the high $\Delta \bar{S}_{\mathrm{S}}$ is attributable to degradations of the 8-membered ring and chains.

\section{Conclusion}

Vapor pressure of sulfur was measured over the sulfur-rich portion of the Tl-S melt. While the thermodynamic activity of sulfur is quite low around $X_{\mathrm{s}}=0.5$, it becomes high in an intermediate range which is in accord with the two liquids separation below $\approx 870^{\circ} \mathrm{K}$. This behaviour was interpreted in terms of the constitutional transition from sulfur of the 8membered ring and chains through $\mathrm{Tl}-\mathrm{S}_{8}-\mathrm{Tl}$ to $\mathrm{Tl}-\mathrm{S}-$ $\mathrm{Tl}\left(\mathrm{Tl}_{2} \mathrm{~S}\right)$. 